\title{
A Comparison Between the Prognosis of Simultaneous and Salvage Radical Resection in Incidental Gallbladder Cancer
}

This article was published in the following Dove Press journal: Cancer Management and Research

\author{
Shilin $\mathrm{He}^{1, *}$ \\ Tunan $\mathrm{Yu}^{\mathrm{l}}{ }^{\text {** }}$ \\ Parikshit Asutosh \\ Khadaroo $\mathbb{D D}^{2,3}$ \\ Liuxin Cai' \\ Yeyuan $\mathrm{Chu}^{4}$ \\ Fangqiang $\mathrm{Wei}^{5}$ \\ Xiao Liang'
}

'Department of General Surgery, Sir Run Run Shaw Hospital, School of Medicine, Zhejiang University, Hangzhou, Zhejiang Province, People's Republic of China; ${ }^{2}$ Monash University, School of Medicine, Nursing and Health Sciences, Melbourne, Australia; ${ }^{3}$ School of Medicine, Zhejiang University, Hangzhou, Zhejiang Province, People's Republic of China; ${ }^{4}$ School of Nursing, Zhejiang Chinese Medical University, Hangzhou, Zhejiang Province, People's Republic of China; ${ }^{5}$ Department of Hepatobiliary and Pancreatic Surgery, Zhejiang Provincial People's Hospital, Hangzhou Medical College, Hangzhou, Zhejiang Province, People's Republic of China

*These authors contributed equally to this work
Correspondence: Xiao Liang

Department of General Surgery, Sir Run Run Shaw Hospital, School of Medicine,

Zhejiang University, 3 East Qingchun

Road, Hangzhou, Zhejiang Province,

People's Republic of China

$\mathrm{Tel} / \mathrm{Fax}+86-57 \mathrm{I}-8600-6605$

Email srrshlx@zju.edu.cn
Purpose: Incidental gallbladder cancer (IGBC) is defined as gallbladder cancer (GBC) that is accidentally discovered during cholecystectomy to treat benign lesions. We aimed to compare the prognosis of IGBC patients who underwent simultaneous radical resection (SIR) vs salvage radical resection (SAR).

Patients and Methods: We retrospectively reviewed data for IGBC patients admitted to Sir Run Run Shaw Hospital from January 2000 to May 2016. Survival analysis was performed using Kaplan-Meier (univariate) and COX regression (multivariate) analyses.

Results: Eighty-four patients with IGBC underwent radical resection; 43/84 underwent SIR, and 41/84 underwent SAR. Compared with SIR, the SAR group was more likely to receive comprehensive preoperative radiographic evaluation, port-site excision, and have more lymph nodes excised (all $\mathrm{P}<0.05$ ). Kaplan-Meier analysis indicated that the prognosis in the SAR group was better than that in SIR (overall survival: $\mathrm{P}=0.050$, recurrence-free survival: $\mathrm{P}=0.028$ ). Regression analysis indicated that the type of radical resection (SIR/ $\mathrm{SAR}$ ) was not an independent prognostic factor (overall survival: $\mathrm{P}=0.737$, recurrence-free survival: $\mathrm{P}=0.957)$.

Conclusion: Patients undergoing SAR had non-inferior survival compared with SIR. It is possible that patients in SAR underwent preoperative radiographical evaluations more comprehensively and the surgical operations were more well performed.

Keywords: incidental gallbladder carcinoma, simultaneous surgery, salvage surgery, prognosis

\section{Introduction}

Gallbladder cancer (GBC) is a type of rare cancer worldwide, and the incidence varies geographically, with higher rates of occurrence in parts of South America and Central and Eastern Asia. The incidence is also high in Hispanic and certain indigenous populations in the americas. ${ }^{1}$ Due to insidious symptoms, most GBC cases are diagnosed at an advanced stage, with an estimated 5-year survival rate of $5-14 \% .^{2-4}$ Currently, surgical resection is the only option to achieve long-term survival in GBC, and adjuvant therapy helps prolong patient survival. ${ }^{5,6}$

Incidental gallbladder cancer (IGBC) is defined as GBC that is unexpectedly discovered in patients undergoing cholecystectomy for benign gallbladder diseases. IGBC was first reported in 1961 by Marcial-Rojas et $\mathrm{al}^{7}$. With the extensive use of laparoscopic cholecystectomy, the incidence of IGBC has been increasing. ${ }^{8}$ For IGBC staged $\geq \mathrm{T} 1 \mathrm{~b}$, simple cholecystectomy results in residual cancerous lesions, 
and causes disease progression and early recurrence. ${ }^{9-11}$ In patients with this stage of IGBC, standardized radical resection should be performed, namely, partial liver parenchymal resection (wedge resection of the gallbladder bed or IVb-V segmental hepatectomy), and lymphatic dissection in the porta hepatis. In cases of IGBC involving extrahepatic bile ducts, resecting the common bile duct and bilioenteric anastomosis may be performed. ${ }^{12}$ However, routine resection of extrahepatic ducts in GBC is not supported by current evidence. ${ }^{13,14}$

When diagnosed by frozen section intraoperatively, radical resection for IGBC should be performed simultaneously. However, when IGBC is discovered in the postoperative pathological examination, a secondary operation, salvage radical resection (SAR) should be considered. This study aims to compare the prognosis of IGBC patients who underwent simultaneous radical resection (SIR) with those who underwent SAR. We hypothesized that survival after SAR is worse than that after SIR. The major reason for this hypothesis was that SAR involves a delay between the cholecystectomy and radical resection, and there is a risk of cancerous dissemination during this delay.

\section{Patients and Methods}

We retrospectively evaluated the medical records of all GBC patients in Sir Run Run Shaw Hospital (SRRSH) between January 2000 and May 2016. Study approval was obtained from the Ethical Committees for Human Subjects at SRRSH, which is affiliated with Zhejiang University, China. Two criteria were used to identify IGBC cases. First, patients were preoperatively diagnosed with benign gallbladder diseases (stone, polyp, adenomyosis) with no sign of malignancy in preoperative radiographic examinations (ultrasonography, computed tomography (CT), or magnetic resonance imaging (MRI)). Second, the diagnosis of GBC was confirmed by intraoperative frozen section or postoperative pathological examination. We excluded patients who did not undergo radical resection or who were failed to follow-up within three months.

Clinical and pathological characteristics were collected from the patients' medical records. Pathological staging was based on the American Joint Committee on Cancer (AJCC) 7th edition classification. Although the AJCC classification was updated to the 8th edition, it was difficult to subdivide stage $\mathrm{T} 2$ cases into the $\mathrm{T} 2 \mathrm{~h}$ and $\mathrm{T} 2 \mathrm{p}$ subgroups according to the 8th edition based on the medical or pathological records in our center; therefore, the 7th edition classification was applied in our study.
Patients' survival data were obtained from the medical records and regular follow-up. The latest date for followup was June 15th, 2019. We used Pearson's $\chi^{2}$ test or Fisher's exact test for the categorical data to compare the distributions of the clinicopathological variables, and the Mann-Whitney $U$-test for continuous variables. Univariate survival analysis was performed using the Kaplan-Meier method (Log-rank test). Variables with $\mathrm{P}<0.10$ were entered into the multivariate Cox regression model. All analyses were performed using SPSS version 22.0 software (IBM Corp., Armonk, NY, USA). A P $<0.05$ was considered statistically significant.

\section{Results}

\section{Selection Process}

From January 2000 to May 2016, 728 patients were diagnosed with GBC in SRRSH, and 169 cases were identified as IGBC. The detail of the selection process is summarized in Figure 1.

Sixty-nine IGBC cases were diagnosed intraoperatively by frozen sections. Amongst the 69 patients, one was diagnosed as Tis and two was diagnosed as T1a by frozen section, which required no further resection. There were six patients refused to undergo further resection intraoperatively, and 15 patients were unsuitable for the curative resection due to the disseminated metastases or unresectable lesions, namely, four patients with hepatic metastases, five patients with peritoneal metastases, two patients with extensive lymphatic metastases, one patient with invasion to the portal vein, one patient with invasion to both the liver and common bile duct, one patient with invasion to the duodenum, and one patient with colonic invasion. Consequently, 45 patients underwent further resection with curative intent, including one patient undergoing R2 resection (unresectable invasion into the pancreas was identified during the resection), and one withdrawal within three months. Finally, 43 patients underwent concurrent radical resection and constituted the SIR group, including two patients with R1 resection (pathological examination suggested positive cystic duct margins) (Figure 1).

One hundred IGBC cases were diagnosed postoperatively. Among the 100 patients, nine were diagnosed as Tis, and two were diagnosed as T1a by pathological examinations, and cholecystectomy alone was considered sufficient. Forty-five patients were considered to have disseminated metastases, unresectable lesions, or the patient declined to undergo reoperation. Therefore, 44 


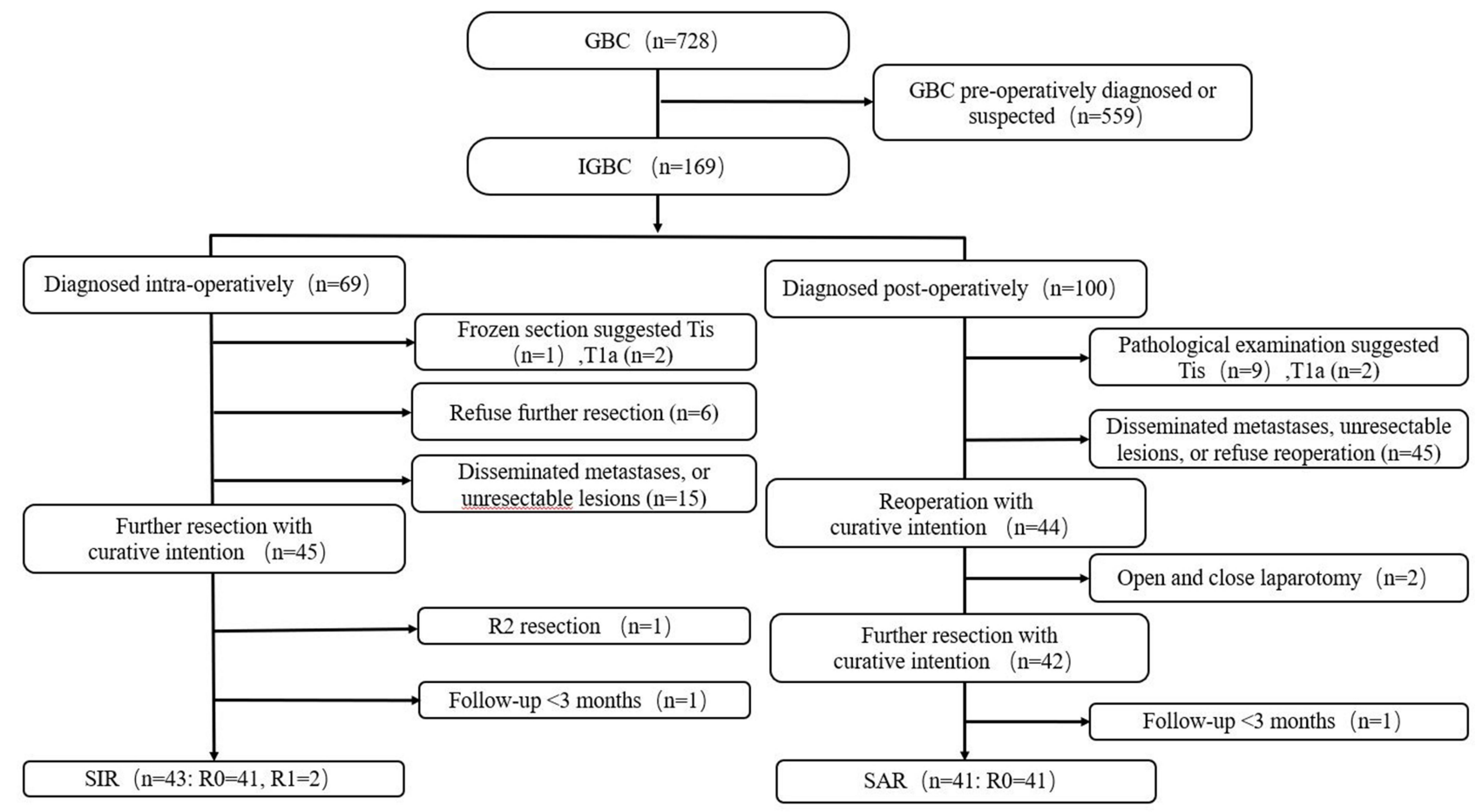

Figure I Selection process for incidental gallbladder cancer patients.

patients underwent reoperation with curative intent, among which two of the 44 patients had peritoneal metastases identified during abdominal exploration, and their surgeons aborted the plan for further resection (open-andclose laparotomy). Forty-two patients went through the radical resection (R0), and one patient withdrew at three months. Consequently, 41 patients were constituted the SAR group (Figure 1).

\section{Patients' Clinicopathological Characteristics}

The median age of all 84 patients (SIR + SAR groups) was 60 years (range: $38-84$ years). Sixty-eight patients $(81.0 \%)$ were women. Based on ultrasonographic examination, 66 patients $(78.6 \%)$ had gallstones, 11 patients (13.1\%) had polyps, five patients $(6.0 \%)$ had both gallstones and polyps, and two patients (2.4\%) had adenomyosis. All patients underwent laparoscopic cholecystectomy first. Eighty-two radical resections were performed via laparotomy (97.6\%), while two patients (2.4\%), one in the SIR group and one in the SAR group, underwent total laparoscopic radical resection. Pathological examination reported six patients (7.1\%) as stage $\mathrm{T} 1 \mathrm{~b}, 62$ patients $(73.8 \%)$ as stage $\mathrm{T} 2$, and the remaining 16 patients $(19.0 \%)$ as stage T3. Seventeen patients $(20.2 \%)$ had lymphatic metastases, nine patients
(10.7\%) had nerve invasion, and six patients $(7.1 \%)$ had microvascular invasion.

The patients' clinicopathological variables are shown in Table 1. The preoperative nutritional status of the two groups, as indicated by albumin, did not differ significantly ( $\mathrm{P}=0.607$ ). The SAR group was more likely to have received comprehensive preoperative radiographic evaluation (enhanced abdominal CT/MRI), port-site excision and more lymph nodes dissected intraoperatively (all $P<0.05)$. Additionally, the SAR group $(21 / 41,51.2 \%)$ was more likely to have had more than six harvested lymph nodes vs the SIR group $(10 / 43,23.3 \%)(\mathrm{P}=$ $0.015)$. It should be noted that there was no significant difference in $\mathrm{T}$ stage and lymph node metastasis between the two groups. Therefore, we believe that the two R1 cases in the SIR group were accidental, rather than caused by more advanced tumors.

\section{Survival Analysis}

The 1-year, 3-year, and 5-year overall survival (OS) rates in the SIR group were $74.4 \%, 50.4 \%$, and $41.4 \%$, respectively, compared with $90.2 \%, 70.6 \%$, and $62.4 \%$ in the SAR group. Kaplan-Meier analysis indicated that the OS in the SAR group was better than SIR group ( $\mathrm{P}=0.050$; Table 2 and Figure 2). 
Table I Comparison of the Clinicopathological Variables Between Patients Undergoing SIR vs SAR

\begin{tabular}{|c|c|c|c|}
\hline Variables & SIR Group & SAR Group & P-value \\
\hline Age (Median, range) & $58(38-84)$ & $59(39-76)$ & 0.497 \\
\hline Sex & & & 0.314 \\
\hline Male & 10 & 6 & \\
\hline Female & 33 & 35 & \\
\hline Albumin (Median, range) & $40.2(31.5-51.3)$ & $40.1(26.0-49.1)$ & 0.607 \\
\hline Enhanced $C T / M R$ examination & & & $<0.001$ \\
\hline Yes & 9 & 41 & \\
\hline No & 34 & 0 & \\
\hline Surgical procedures & & & 0.321 \\
\hline Hepatic wedge resection & 42 & 37 & \\
\hline + lymphadenectomy of porta hepatis & & & \\
\hline Hepatic wedge resection & I & 3 & \\
\hline +resection of common bile duct & & & \\
\hline +choledochojejunostomy & & & \\
\hline +lymphadenectomy of porta hepatis & & & \\
\hline Hepatic segmental resection (V, VI, VII) & 0 & $\mathrm{I}$ & \\
\hline +lymphadenectomy of porta hepatis & & & \\
\hline Port-site resection & & & 0.001 \\
\hline Yes & 0 & 10 & \\
\hline No & 43 & 31 & \\
\hline Dissected lymph node (Median, range) & $5(I-14)$ & $6(I-23)$ & 0.009 \\
\hline Dissected lymph nodes (cut-off level as 6) & & & 0.015 \\
\hline$>6$ & 10 & 20 & \\
\hline$\leq 6$ & 33 & 21 & \\
\hline T stage & & & 0.253 \\
\hline TIb & 5 & I & \\
\hline $\mathrm{T} 2$ & 29 & 33 & \\
\hline T3 & 9 & 7 & \\
\hline Lymphatic metastasis & & & 0.138 \\
\hline Present & 12 & 6 & \\
\hline Absent & 31 & 35 & \\
\hline Grade of differentiation & & & 0.899 \\
\hline GI & 21 & 22 & \\
\hline G2 & 5 & 4 & \\
\hline G3\&G4 & 17 & 15 & \\
\hline Nerve invasion & & & 0.125 \\
\hline Present & 8 & 3 & \\
\hline Absent & 35 & 38 & \\
\hline Microvascular invasion & & & 0.266 \\
\hline Present & 6 & 2 & \\
\hline Absent & 37 & 39 & \\
\hline Adjuvant therapy & & & 0.884 \\
\hline Yes & 13 & 13 & \\
\hline No & 30 & 28 & \\
\hline
\end{tabular}

Abbreviations: SIR, simultaneous radical resection; SAR, salvage radical resection; CT, computed tomography; MR, magnetic resonance. 
Table 2 Univariate Analysis for Prognostic Variables in IGBC

\begin{tabular}{|c|c|c|c|c|c|}
\hline \multirow[t]{2}{*}{ Variables } & \multirow[t]{2}{*}{ Comparison } & \multicolumn{2}{|l|}{ OS } & \multicolumn{2}{|l|}{ RFS } \\
\hline & & $\chi^{2}$ & P-value & $\chi^{2}$ & P-value \\
\hline Age & $\leq 65$ vs $>65$ & 0.020 & 0.967 & 0.122 & 0.727 \\
\hline Sex & Male vs Female & 1.416 & 0.234 & 0.258 & 0.611 \\
\hline Enhanced $C T / M R$ examination & Yes vs No & 4.278 & $0.038 *$ & 4.714 & $0.030 *$ \\
\hline Type of radical resection & SIR vs SAR & 3.853 & $0.050 *$ & 4.822 & $0.028 *$ \\
\hline Port-site resection & Yes vs No & 1.938 & 0.164 & 2.089 & 0.148 \\
\hline $\mathrm{T}$ stage & TIb vs T2 vs T3 & 23.927 & $<0.001 *$ & 19.786 & $<0.001 *$ \\
\hline Lymphatic metastases & Present vs Absent & 14.924 & $<0.00 I^{*}$ & 12.568 & $<0.001 *$ \\
\hline Dissected lymph nodes & $\leq 6$ vs $>6$ & 2.608 & 0.106 & 3.351 & $0.067^{*}$ \\
\hline Grade of differentiation & GI vs $G 2$ vs $G 3 \& G 4$ & 13.909 & $0.001 *$ & 13.240 & $0.001 *$ \\
\hline Nerve invasion & Present vs Absent & 1.004 & 0.316 & 2.863 & $0.09 I^{*}$ \\
\hline Microvascular invasion & Present vs Absent & 13.416 & $<0.00 I^{*}$ & 12.829 & $<0.001 *$ \\
\hline Adjuvant therapy & Yes vs No & 0.543 & 0.474 & 0.830 & 0.362 \\
\hline
\end{tabular}

Note: *Variables with P-value $<0.10$, and further analyzed with COX model.

Abbreviations: OS, overall survival; RFS, recurrence-free survival; vs, versus; SIR, simultaneous radical resection; SAR, salvage radical resection; CT, computed tomography; MR, magnetic resonance.

The 1-year, 3-year, and 5-year recurrence-free survival (RFS) rates in the SIR group were $60.5 \%, 40.8 \%$, and $35 \%$, respectively, compared with $82.9 \%, 62.7 \%$, and $62.7 \%$ in the SAR group. Kaplan-Meier analysis indicated that the RFS in the SAR group was better than SIR group $(\mathrm{P}=0.028$; Table 2 and Figure 3).

In the regression analysis, $\mathrm{T}$ stage, lymphatic metastasis, and grade of differentiation were independent prognostic factors (all $\mathrm{P}<0.05$ ), while the type of radical resection (SIR/SAR) was not $(\mathrm{OS}: \mathrm{P}=0.737$, RFS: $\mathrm{P}=$ 0.957; Table 3).

\section{Time Interval Analysis}

In the SAR group, the time interval from the date of initial cholecystectomy to the date of salvage operation differed by subgroup. We divided the SAR group into three groups: intA group, with an interval of $<$ two weeks (11 patients); intB group, with an interval between two and four weeks (19 patients); and intC group, with an interval $>$ four weeks (11 patients). Survival analysis showed that the prognosis of the intB group was statistically superior to that of the SIR group $(\mathrm{P}<0.05)$. However, there were no statistical differences between the SIR and intA groups ( $\mathrm{P}$ $=0.797)$. We also found no statistical difference between the SIR and intC groups $(\mathrm{P}=0.192$; Figure 4$)$.

\section{Discussion}

It is estimated that $50-70 \%$ of GBCs are diagnosed accidentally by the pathological examination during or after surgery, ${ }^{10,15,16}$ and these cancers are termed IGBC. The incidence of IGBC after cholecystectomy is $0.25 \%$ $3 \%{ }^{17,18}$ Performing frozen section histopathology is the most effective way to detect IGBC intraoperatively and minimize the likelihood of secondary surgery. However, reckoning that cholecystectomy is a mature technique and globally performed as routine procedure, the increased medical costs and prolonged operative time caused by the use of frozen section histopathology is considerably high. ${ }^{19,20}$ Some researchers held the opinion that IGBC occurred rarely in macroscopically normal cholecystectomy specimens, and a "selective strategy" was adopted based on the macroscopic abnormalities of the gross specimens. ${ }^{21-25}$ In SRRSH, we used frozen section histopathology selectively in laparoscopic cholecystectomies. Every gross gallbladder specimen was examined by the chief surgeons, and intraoperative frozen section histopathology was performed when a cancerous lesion was suspected, for instance, when the gallbladder wall was thickened or there was a mass invading the gallbladder mucosa. However, it was concerned that tumor size in patients undergoing SIR may be larger than that of SAR. Therefore, we compared patients' clinicopathological characteristics between the SIR and SAR groups (Table 1) and found no significant differences in T stage, lymphatic metastasis, grade of differentiation, and microvascular and nerve invasion (all $\mathrm{P}>0.05$ ). Furthermore, we used a COX regression model to adjust for the effect of potential confounding covariates.

To our knowledge, it is the first time that the outcome of patients undergoing SAR were directly compared with SIR. 


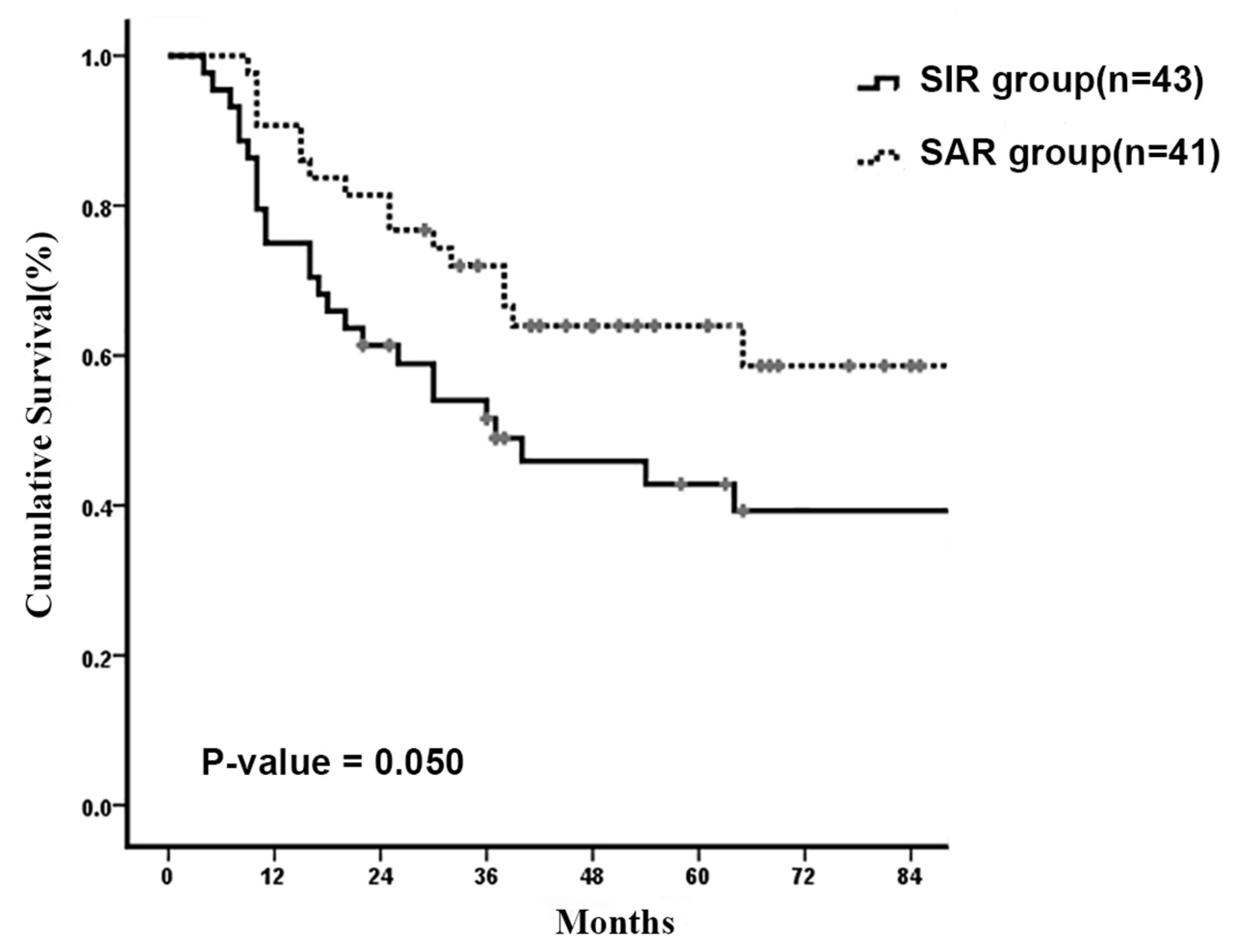

Figure 2 Kaplan-Meier survival curve for overall survival in incidental gallbladder cancer.

Abbreviations: SIR, simultaneous radical resection; SAR, salvage radical resection.

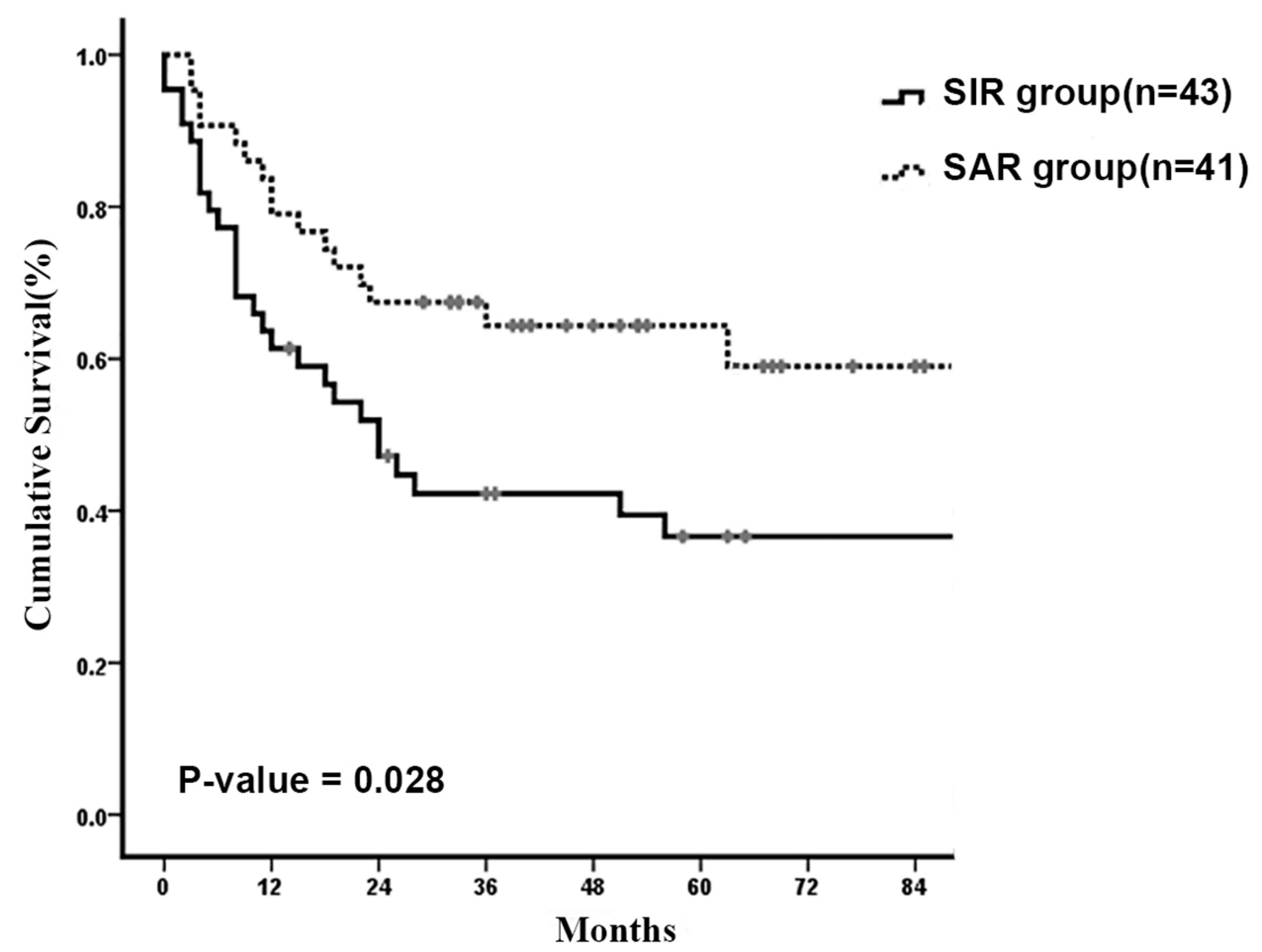

Figure 3 Kaplan-Meier survival curve for recurrence-free survival in incidental gallbladder cancer.

Abbreviations: SIR, simultaneous radical resection; SAR, salvage radical resection. 
Table 3 Multivariate Analysis of Prognostic Risk Factors for Survival After Incidental Gallbladder Cancer Surgery Using Cox Regression Model

\begin{tabular}{|c|c|c|c|c|c|}
\hline \multirow[t]{2}{*}{ Variables } & \multirow[t]{2}{*}{ Group } & \multicolumn{2}{|l|}{ OS } & \multicolumn{2}{|l|}{ RFS } \\
\hline & & HR (95\% Cl) & P-value & HR (95\% Cl) & P-value \\
\hline Type of radical resection & $\begin{array}{l}\text { SIR } \\
\text { SAR }\end{array}$ & $\begin{array}{l}\text { Ref. } \\
0.824(0.266 \sim 2.548)\end{array}$ & 0.737 & $\begin{array}{l}\text { Ref. } \\
0.97 \mid(0.336 \sim 2.806)\end{array}$ & 0.957 \\
\hline T stage & $\begin{array}{l}\text { T3 } \\
\text { T2 } \\
\text { TIb }\end{array}$ & $\begin{array}{l}\text { Ref. } \\
0.179(0.02 \mathrm{I} \sim 1.55 \mathrm{I}) \\
0.287(0.135 \sim 0.6 \mathrm{I} 0)\end{array}$ & $\begin{array}{l}0.004^{*} \\
0.119 \\
0.001 *\end{array}$ & $\begin{array}{l}\text { Ref. } \\
0.223(0.025 \sim 1.979) \\
0.278(0.131 \sim 0.587)\end{array}$ & $\begin{array}{l}0.003^{*} \\
0.178 \\
0.001 *\end{array}$ \\
\hline Lymphatic metastases & $\begin{array}{l}\text { Absent } \\
\text { Present }\end{array}$ & $\begin{array}{l}\text { Ref. } \\
2.308 \text { (I.098 4.852) }\end{array}$ & $0.027^{*}$ & $\begin{array}{l}\text { Ref. } \\
\text { I.779(0.790 4.005) }\end{array}$ & 0.164 \\
\hline Grade of differentiation & $\begin{array}{l}\text { GI } \\
\text { G2 } \\
\text { G3\&G4 }\end{array}$ & $\begin{array}{l}\text { Ref. } \\
3.725 \text { (1.319 10.519) } \\
2.415 \text { (1.160 5.028) }\end{array}$ & $\begin{array}{l}0.016^{*} \\
0.013^{*} \\
0.018^{*}\end{array}$ & $\begin{array}{l}\text { Ref. } \\
4.330(1.48 \sim 12.663) \\
3.059(1.324 \sim 7.065)\end{array}$ & $\begin{array}{l}0.009 * \\
0.007^{*} \\
0.009 *\end{array}$ \\
\hline Microvascular invasion & $\begin{array}{l}\text { Absent } \\
\text { Present }\end{array}$ & $\begin{array}{l}\text { Ref. } \\
\text { I.87| (0.742 4.720) }\end{array}$ & 0.185 & $\begin{array}{l}\text { Ref. } \\
\text { I.535(0.594 3.968) }\end{array}$ & 0.376 \\
\hline Enhanced CT/MR examination & $\begin{array}{l}\text { No } \\
\text { Yes }\end{array}$ & $\begin{array}{l}\text { Ref. } \\
0.776(0.250 \sim 2.408)\end{array}$ & $0.66 \mathrm{I}$ & $\begin{array}{l}\text { Ref. } \\
0.744(0.264 \sim 2.098)\end{array}$ & 0.576 \\
\hline Nerve invasion & $\begin{array}{l}\text { Absent } \\
\text { Present }\end{array}$ & $\begin{array}{l}- \\
-\end{array}$ & $\begin{array}{l}- \\
- \\
-\end{array}$ & $\begin{array}{l}\text { Ref. } \\
2.650(0.902 \sim 7.784)\end{array}$ & 0.76 \\
\hline Dissected lymph nodes & $\begin{array}{l}\leq 6 \\
>6\end{array}$ & $\begin{array}{l}- \\
-\end{array}$ & $\begin{array}{l}- \\
- \\
-\end{array}$ & $\begin{array}{l}\text { Ref. } \\
0.582(0.270 \sim 1.253)\end{array}$ & 0.167 \\
\hline
\end{tabular}

Note: *Variables with P-value $<0.05$.

Abbreviations: OS, overall survival; RFS, recurrence-free survival; HR, hazard ratio; Cl, confidence interval; Ref, reference; SIR, simultaneous radical resection; SAR, salvage radical resection; $\mathrm{CT}$, computed tomography; $\mathrm{MR}$, magnetic resonance.

The major finding in this study was that in IGBC, patients undergoing SAR had non-inferior survival compared with patients undergoing SIR (OS: $\mathrm{P}=0.737$, RFS: $\mathrm{P}=0.957$ ). Our study suggested that high-quality SAR might also achieve optimal long-term prognosis in IGBC. It provided evidence that SAR surgery may also be helpful for IGBC patients detected postoperatively. Still, it should be noted that detailed imaging evaluation and sufficient excised nodes are necessary. We speculate that there are two reasons for this difference from previous hypothesis. First, preoperative radiographic evaluation in the SAR group was more comprehensive; almost all patients in the SAR group underwent abdominal enhanced CT/MRI preoperatively, compared with $20.9 \%$ of patients in the SIR group. High-quality CT and
MRI certainly helps to detect lymph node metastasis, peripheral organ invasion, and distant metastasis, thereby aiding better development of surgical procedures. ${ }^{26-28}$ Second, radical resection in the SAR group was of higher quality, especially including the lymphatic and port-site resection. A sufficient number of excised nodes help with accurate lymphatic staging and can potentially improve long-term prognosis. ${ }^{29-31}$ We analyzed the number of patients who received adequate lymphadenectomy in each cohort. The cut-off value for lymph node dissection number was set at six according to the 8th AJCC staging manual. ${ }^{32}$ Our results showed that the SAR group $(21 / 41,51.2 \%)$ was more likely to have had more than six excised lymph nodes vs the SIR group $(10 / 43,23.3 \%)(P=0.015)$. 


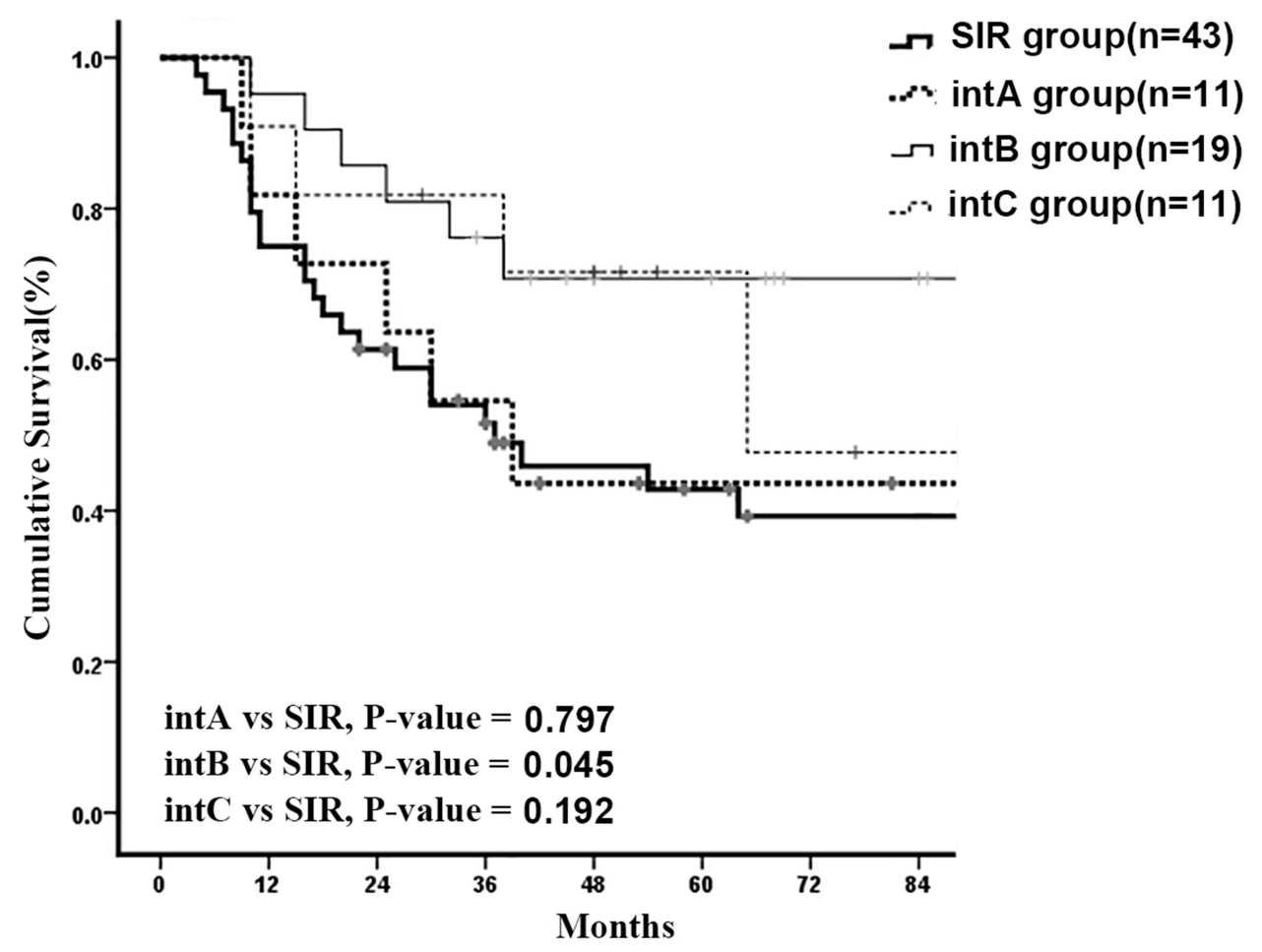

Figure 4 Time interval analysis for incidental gallbladder cancer patients undergoing previous cholecystectomy and delayed resection. Abbreviations: SIR, simultaneous radical resection; intA, interval <2 weeks; intB, interval between 2 and 4 weeks; intC, interval >4 weeks.

Several studies suggested that port-site resection does not improve long-term survival in GBC patients, such as the multi-institutional analysis of Ethun et $\mathrm{al}^{33}$ in 2017 and the systematic review performed by Soreide et $\mathrm{al}^{34}$. However, the port-site resections in the 10 patients in our study were performed before 2014 when the therapeutic value of this procedure was controversial and inconclusive. In the SAR group, 10 patients underwent port-site resection, while none of the patients in the SIR group underwent this procedure.

For IGBC diagnosed postoperatively, the optimum time interval from original cholecystectomy to SAR is controversial. Ethun et $\mathrm{al}^{35}$ retrospectively analyzed 449 patients from 10 institutions in the USA and suggested that the optimal time interval was 4-8 weeks. The authors believed that secondary resection too soon after the first surgery may not allow sufficient time for subclinical disease to present, while if too late, disease dissemination could occur. In our study, patients in the subgroup with an interval of 2-4 weeks (intB subgroup) had the best prognosis within the SAR group. However, it should be noted that there may be significant bias in this analysis of interoperative time interval because the number of patients in both the intA and intC groups was small $(\mathrm{n}=11$, each).
More researches are required to be done in the future concerning the right timing for secondary resection.

There are several limitations to be mentioned in our study. First, we evaluated data from a single tertiary center. Considering the low incidence of IGBC in routine cholecystectomy, data from multicenter studies would provide more concrete evidence. Second, some clinical information, such as bile spillage, was not recorded and thus could not be collected for analysis in this study. ${ }^{36}$ Intraoperative bile spillage could cause cancer cells to spread out of the gallbladder, causing the original disease to progress and upgrade. $^{37}$ Third, laparoscopic exploration ${ }^{38}$ (one patient in the SAR group) and radical resection ${ }^{39}$ (one patient in the SIR group and one patient in the SAR group) were used rarely in this study. The effects of these procedures on long-term prognosis were not analyzed because of the small numbers of patients undergoing these procedures. Additionally, because of insufficient patient volume, our data were unable to investigate the effect of SIR/SAR on margin status. Finally but importantly, the majority of patients in this study were T2 stage, and therefore, the long-term prognosis in this study was optimistic considering the extreme malignancy of GBC (5-year OS, 41.4\% for the SIR group and $62.4 \%$ for the SAR group). In IGBC 
with extensive invasion or severe residual disease, ${ }^{11}$ whether large-scale resections such as major hepatectomy or pancreatoduodenectomy ${ }^{40}$ prolong survival is currently unknown.

\section{Conclusions}

In this study, patients undergoing SAR had non-inferior survival compared with SIR, possibly benefited from more comprehensive preoperative radiographic evaluations and higher-quality of surgical operations.

\section{Ethics Approval}

This study was approved by the Ethics Committee of Sir Run Run Shaw Hospital of Zhejiang University (Approval no. 20,200,225-36). The need for informed patient consent was waived because of the retrospective nature of the study. As a retrospective study, waiver of informed consent was approved by the Ethics Committee of Sir Run Run Shaw Hospital of Zhejiang University. This study protected patient data confidentiality and was in compliance with the Declaration of Helsinki.

\section{Acknowledgments}

We thank Jane Charbonneau, DVM, from Liwen Bianji, Edanz Group China (www.liwenbianji.cn/ac), for editing the English text of a draft of this manuscript.

\section{Funding}

This work was supported by the Zhejiang Medical Science and Technology Project (2018KY488), Hangzhou Medical Science and Technology Project (2015A54), Zhejiang Provincial Natural Science Foundation (Y15H160052), Medical Health Science and Technology Project of Zhejiang Provincial Health Commission (2019PY038), and the Open Fund of the Shanghai Key Laboratory of Biliary Tract Disease Research, Shanghai, China (SKLBTDROF-20190003).

\section{Disclosure}

The authors report no conflicts of interest in this work.

\section{References}

1. Miranda-Filho A, Pineros M, Ferreccio C, et al. Gallbladder and extrahepatic bile duct cancers in the Americas: incidence and mortality patterns and trends. Int $J$ Cancer. 2020;147:978-989. doi:10.1002/ ijc. 32863

2. Shindoh J, de Aretxabala X, Aloia TA, et al. Tumor location is a strong predictor of tumor progression and survival in T2 gallbladder cancer an international multicenter study. Ann Surg. 2015;261(4):733-739.
3. Zeng H, Chen W, Zheng R, et al. Changing cancer survival in China during 2003-15: a pooled analysis of 17 population-based cancer registries. Lancet Glob Health. 2018;6(5):e555-e567. doi:10.1016/ S2214-109X(18)30127-X

4. Goetze TO. Gallbladder carcinoma: prognostic factors and therapeutic options. World J Gastroenterol. 2015;21(43):12211-12217. doi:10.3748/wjg.v21.i43.12211

5. Kasumova GG, Tabatabaie O, Najarian RM, et al. Surgical management of gallbladder cancer: simple versus extended cholecystectomy and the role of adjuvant therapy. Ann Surg. 2017;266(4):625-631. doi:10.1097/SLA.0000000000002385

6. Horgan AM, Amir E, Walter T, Knox JJ. Adjuvant therapy in the treatment of biliary tract cancer: a systematic review and meta-analysis. $J$ Clin Oncol. 2012;30(16):1934-1940. doi:10.1200/JCO.2011.40.5381

7. Marcial-Rojas RA, Medina R. Unsuspected carcinoma of the gallbladder in acute and chronic cholecystitis. Ann Surg. 1961;153:289298. doi:10.1097/00000658-196102000-00018

8. Koshenkov VP, Koru-Sengul T, Franceschi D, Dipasco PJ, Rodgers SE. Predictors of incidental gallbladder cancer in patients undergoing cholecystectomy for benign gallbladder disease. J Surg Oncol. 2013;107(2):118-123.

9. Vinuela E, Vega EA, Yamashita S, et al. Incidental gallbladder cancer: residual cancer discovered at oncologic extended resection determines outcome: a report from high- and low-incidence countries. Ann Surg Oncol. 2017;24(8):2334-2343. doi:10.1245/s10434-017-5859-6

10. Choi KS, Choi SB, Park P, Kim WB, Choi SY. Clinical characteristics of incidental or unsuspected gallbladder cancers diagnosed during or after cholecystectomy: a systematic review and meta-analysis. World J Gastroenterol. 2015;21(4):1315-1323. doi:10.3748/ wjg.v21.i4.1315

11. Butte JM, Kingham TP, Gonen M, et al. Residual disease predicts outcomes after definitive resection for incidental gallbladder cancer. $J \mathrm{Am}$ Coll Surg. 2014;219(3):416-429. doi:10.1016/j.jamcollsurg.2014.01.069

12. Nishio H, Ebata T, Yokoyama Y, Igami T, Sugawara G, Nagino M. Gallbladder cancer involving the extrahepatic bile duct is worthy of resection. Ann Surg. 2011;253(5):953-960. doi:10.1097/SLA.0b013 e318216f5f3

13. Nigri G, Berardi G, Mattana C, et al. Routine extra-hepatic bile duct resection in gallbladder cancer patients without bile duct infiltration: a systematic review. Surgeon. 2016;14(6):337-344.

14. Shukla PJ, Barreto SG. Systematic review: should routine resection of the extra-hepatic bile duct be performed in gallbladder cancer? Saudi J Gastroenterol. 2010;16(3):161-167. doi:10.4103/13193767.65184

15. Fuks D, Regimbeau JM, Le Treut YP, et al. Incidental gallbladder cancer by the AFC-GBC-2009 Study Group. World J Surg. 2011;35 (8):1887-1897. doi:10.1007/s00268-011-1134-3

16. Ethun CG, Postlewait LM, Le N, et al. A novel pathology-based preoperative risk score to predict locoregional residual and distant disease and survival for incidental gallbladder cancer: a 10-institution study from the U.S. extrahepatic biliary malignancy consortium. Ann Surg Oncol. 2017;24(5):1343-1350. doi:10.1245/s10434-016-5637-x

17. Kim JH, Kim WH, Kim JH, Yoo BM, Kim MW. Unsuspected gallbladder cancer diagnosed after laparoscopic cholecystectomy: focus on acute cholecystitis. World J Surg. 2010;34(1):114-120.

18. Cavallaro A, Piccolo G, Panebianco V, et al. Incidental gallbladder cancer during laparoscopic cholecystectomy: managing an unexpected finding. World J Gastroenterol. 2012;18(30):4019-4027. doi:10.3748/wjg.v18.i30.4019

19. Deng YL, Xiong XZ, Zhou Y, Shrestha A, Li FY, Cheng NS. Selective histology of cholecystectomy specimens-is it justified? $J$ Surg Res. 2015;193(1):196-201. doi:10.1016/j.jss.2014.07.039

20. Jayasundara JA, de Silva WM. Histological assessment of cholecystectomy specimens performed for symptomatic cholelithiasis: routine or selective? Ann R Coll Surg Engl. 2013;95(5):317-322. doi:10.13 08/003588413X13629960046471 
21. Emmett CD, Barrett P, Gilliam AD, Mitchell AI. Routine versus selective histological examination after cholecystectomy to exclude incidental gallbladder carcinoma. Ann R Coll Surg Engl. 2015;97 (7):526-529.

22. Elshaer M, Gravante G, Yang Y, et al. Routine versus selective histologic analysis of gallbladder specimens for the detection of incidental gallbladder cancers. A retrospective review over 9 years of activity with a special focus on patients' age. Am J Surg. 2014;208 (3):444-449. doi:10.1016/j.amjsurg.2013.12.038

23. Lundgren L, Muszynska C, Ros A, et al. Are incidental gallbladder cancers missed with a selective approach of gallbladder histology at cholecystectomy? World J Surg. 2018;42(4):1092-1099.

24. Wrenn SM, Callas PW, Abu-Jaish W. Histopathological examination of specimen following cholecystectomy: are we accepting resect and discard? Surg Endosc. 2017;31(2):586-593. doi:10.1007/s00464-0165002-y

25. Patel K, Dajani K, Iype S, et al. Incidental non-benign gallbladder histopathology after cholecystectomy in an United Kingdom population: need for routine histological analysis? World $J$ Gastrointest Surg. 2016;8(10):685-692.

26. Furlan A, Ferris JV, Hosseinzadeh K, Borhani AA. Gallbladder carcinoma update: multimodality imaging evaluation, staging, and treatment options. AJR Am J Roentgenol. 2008;191(5):1440-1447. doi:10.2214/AJR.07.3599

27. Joo I, Lee JY, Baek JH, et al. Preoperative differentiation between $\mathrm{T} 1 \mathrm{a}$ and $>/=\mathrm{T} 1 \mathrm{~b}$ gallbladder cancer: combined interpretation of highresolution ultrasound and multidetector-row computed tomography. Eur Radiol. 2014;24(8):1828-1834.

28. Kim SJ, Lee JM, Lee ES, Han JK, Choi BI. Preoperative staging of gallbladder carcinoma using biliary MR imaging. J Magn Reson Imaging. 2015;41(2):314-321. doi:10.1002/jmri.24537

29. Han HS, Yoon YS, Agarwal AK, et al. Laparoscopic surgery for gallbladder cancer: an expert consensus statement. Dig Surg. 2019;36 (1):1-6. doi:10.1159/000486207

30. Aloia TA, Jarufe N, Javle M, et al. Gallbladder cancer: expert consensus statement. HPB. 2015;17(8):681-690. doi:10.1111/hpb.12444

31. Negi SS, Singh A, Chaudhary A. Lymph nodal involvement as prognostic factor in gallbladder cancer: location, count or ratio? $J$ Gastrointest Surg. 2011;15(6):1017-1025.
32. Chun YS, Pawlik TM, Vauthey JN. 8th edition of the AJCC cancer staging manual: pancreas and hepatobiliary cancers. Ann Surg Oncol. 2018;25(4):845-847. doi:10.1245/s10434-017-6025-x

33. Ethun CG, Postlewait LM, Le N, et al. Routine port-site excision in incidentally discovered gallbladder cancer is not associated with improved survival: a multi-institution analysis from the US Extrahepatic Biliary Malignancy Consortium. J Surg Oncol. 2017;115(7):805-811. doi:10.1002/jso.24591

34. Soreide K, Guest RV, Harrison EM, Kendall TJ, Garden OJ, Wigmore SJ. Systematic review of management of incidental gallbladder cancer after cholecystectomy. Br J Surg. 2019;106(1):32-45. doi:10.1002/bjs.11035

35. Ethun CG, Postlewait LM, Le N, et al. Association of optimal time interval to re-resection for incidental gallbladder cancer with overall survival: a multi-institution analysis from the US Extrahepatic Biliary Malignancy Consortium. JAMA Surg. 2017;152(2):143-149. doi:10. 1001/jamasurg.2016.3642

36. Horkoff MJ, Ahmed $\mathrm{Z}, \mathrm{Xu} \mathrm{Y}$, et al. Adverse outcomes after bile spillage in incidental gallbladder cancers: a population-based study. Ann Surg. 2019. doi:10.1097/SLA.0000000000003325

37. Blakely AM, Wong $\mathrm{P}$, Chu $\mathrm{P}$, et al. Intraoperative bile spillage is associated with worse survival in gallbladder adenocarcinoma. J Surg Oncol. 2019;120(4):603-610.

38. Butte JM, Gonen M, Allen PJ, et al. The role of laparoscopic staging in patients with incidental gallbladder cancer. HPB. 2011;13(7):463472. doi:10.1111/j.1477-2574.2011.00325.x

39. Dou C, Zhang Y, Liu J, et al. Laparoscopy versus laparotomy approach of a radical resection for gallbladder cancer: a retrospective comparative study. Surg Endosc. 2019.

40. Mizuno T, Ebata T, Yokoyama Y, et al. Major hepatectomy with or without pancreatoduodenectomy for advanced gallbladder cancer. $\mathrm{Br}$ J Surg. 2019;106(5):626-635. doi:10.1002/bjs.11088

\section{Publish your work in this journal}

Cancer Management and Research is an international, peer-reviewed open access journal focusing on cancer research and the optimal use of preventative and integrated treatment interventions to achieve improved outcomes, enhanced survival and quality of life for the cancer patient.
The manuscript management system is completely online and includes a very quick and fair peer-review system, which is all easy to use. Visit http://www.dovepress.com/testimonials.php to read real quotes from published authors. 